\title{
Understanding nitrogen recovery from wastewater with a high nitrogen concentration using microbial electrolysis cells
}

\author{
M. Isabel San-Martín ${ }^{1}$, Raúl Mateos ${ }^{1}$, Adrián Escapa ${ }^{1,2}$, Antonio Morán ${ }^{1 *}$ \\ ${ }^{1}$ Chemical and Environmental Bioprocess Engineering Group, Natural Resources Institute \\ (IRENA), Universidad de León, Avda. de Portugal 41, Leon 24009, Spain \\ ${ }^{2}$ Department of Electrical Engineering and Automatic Systems, Universidad de León, Campus \\ de Vegazana s/n, 24071 León, Spain
}

\begin{abstract}
This study was aimed at understanding the effect of applied voltage, catholyte and reactor scale on nitrogen recovery from two different organic wastes (digestate and pig slurry) by means of microbial electrolysis cell (MEC) technology. For this purpose, MEC sizes of 100, 500 and 1000 $\mathrm{mL}$ were tested at applied voltages of $0.6,1$ and $1.4 \mathrm{~V}$ using either a phosphate-buffered solution or $\mathrm{NaCl}$ solution as the catholyte. By increasing the reactor size from $500 \mathrm{~mL}$ to $1000 \mathrm{~mL}$, a decrease in the ammonia recovery efficiency from 47 to $42 \%$ was observed. The results also showed that the phosphate-buffered solution is preferable as the catholyte and that the voltage applied does not have a noticeable effect on current production and ammonia recovery. Low biodegradability of the wastes was identified as the main bottleneck.
\end{abstract}




\author{
*Address correspondence to Antonio Morán, Universidad de León, Avda. de Portugal 41, Leon \\ 24009, Spain; Phone: 987291841; \\ E-mail: amorp@unileon.es
}

\begin{abstract}
KEYWORDS: Microbial electrolysis cell, ammonia recovery, high nitrogen concentration wastewater, scaling up.
\end{abstract}

\title{
Introduction
}

Livestock products and digestate are commonly used as fertilisers for crop production due to their high nutrient content ${ }^{[1]}$. However, their direct disposal may also overcome the capacity of the soil to absorb nutrients in some areas ${ }^{[2]}$, giving to rise to health and environmental issues such as the eutrophication of water bodies ${ }^{[3]}$. In addition, waste logistics (collection, storage and transport) represent a significant cost for farmers, and much of the nitrogen is lost due to $\mathrm{NH}_{3}$ emission $(18 \%$ of the $\mathrm{N})$ and $\mathrm{N}_{2}$ production $(26 \%$ of the $\mathrm{N})$ during storage ${ }^{[4]}$. Nevertheless, these wastes could also be considered a valuable resource if the nitrogen contained in the manure and digestate could be used as fertiliser. Li et al. ${ }^{[5]}$ supported the idea that the recovery of nitrogen from wastewater (WW) can form part of the existing nitrogen-fertiliser production process. Therefore, if the nitrogen contained in manure and digestate (higher than in WW) could 
be feasibly and efficiently recovered, it would reduce the environmental impact and economic cost of the energy-intensive fertiliser manufacturing process and it would avoid ammonia inhibition during anaerobic digestion ${ }^{[6][7]}$.

Bioelectrochemical systems (BES) represent an emerging technology with a wide range of potential applications ranging from energy valorisation of swine wastes ${ }^{[8]}$ to water desalination, or indeed the recovery of nutrients from waste streams ${ }^{[9]}$. For nitrogen in particular, this can be accomplished by allowing ammonia to cross from the anolyte to the catholyte thanks to diffusion and migration phenomena ${ }^{[10][11]}$. This enables ammonium to be separated and concentrated on the catholyte ${ }^{[12]}$, then subsequently stripped in an air-stripping system and recovered in acid. This strategy has been previously described and tested by Kuntke et al. ${ }^{[13]}$ using a microbial fuel cell (MFC), with an ammonium recovery rate of $3.29 \mathrm{gN} \cdot \mathrm{m}^{-2} \cdot \mathrm{day}^{-1}$, and in a microbial electrolysis cell (MEC) by Wu and Modin ${ }^{[14]}$, who reported up to $79 \%$ ammonia recovery. Although this strategy has already been reported as a sustainable process for nitrogen recovery with WW, there is still a lack of knowledge about how this technology performs when using real substrates. Although real substrates may contain a high nitrogen concentration, organic matter is not readily accessible by electrogenic microorganisms, which hampers current production, and thus, ammonia migration.

The aim of this research was to study the feasibility of nitrogen recovery from two different organic wastes using MEC technology, and to understand how the applied voltage, the type of 
catholyte and the reactor size affects the overall performance. Experiments were carried out in $100 \mathrm{~mL}$ (MEC-1X), $500 \mathrm{~mL}$ (MEC-5X) and $1000 \mathrm{~mL}$ (MEC-10X) capacity MEC reactors at applied voltages of $0.6,1.0$ and $1.4 \mathrm{~V}$, using either a phosphate-buffered solution (PBS) or $\mathrm{NaCl}$ solution as the catholyte.

\section{Materials and methods}

\section{MEC-1X test}

Four similar methacrylate MECs were used, consisting of four methacrylate plates coupled in parallel with a rubber sheet inserted between each plate. The two sides of the plates acted as the walls of the reactor, while the central plates had been emptied and acted as anodic or cathodic chambers holding $50 \mathrm{~mL}$ each (anode and cathode). The electrodes were made of 5-mm-thick graphite felt and stainless steel mesh for the anode and cathode, respectively. The felt was pretreated following a method described elsewhere ${ }^{[15]}$, and the stainless steel was cleaned with distilled water. Both electrodes were connected to a titanium wire to facilitate the connection, and a cation exchange membrane (CEM) (CMI-7000; Membranes International Inc., USA) was placed between both compartments. Assays were performed in batches at $30^{\circ} \mathrm{C}$, and the power supply was computer-controlled using an analog output board (PCI-6713; National Instruments, 
USA). The voltage was measured and recorded every 10 min across a $16-\Omega$ fixed resistor using a data acquisition system that was connected to a computer.

The anodes of all MECs were inoculated with sewage sludge and effluent from the bioanode of a previous MEC that had been supplemented with $0.5 \mathrm{~g} \cdot \mathrm{L}^{-1}$ of acetate. The anode feed consisted of either digestate from an anaerobic digester of an urban WW treatment plant (located in the northwest of Spain) or pig slurry from a nearby pig farm (the composition of both feeds is indicated in Table 1). The catholyte consisted of either PBS ( $0.1 \mathrm{M})$ or $\mathrm{NaCl}$ solution $(0.1 \mathrm{M})$. For MEC-1x, tests to determine the effect of different catholytes ( $\mathrm{NaCl}$ and $\mathrm{PBS})$ and the applied potential $(0.6,1$ and $1.4 \mathrm{~V})$ were performed, all of which were conducted over a period of 48 hours. Samples of the liquid were taken at 2, 4.5, 7.5, 28, 32 and 48 hours.

\section{MEC-5X and MEC-10X tests}

The MEC-5X and MEC-10X tests used two reactors with the same configuration as MEC-1X, but with a volume per chamber of $250 \mathrm{~mL}$ and $500 \mathrm{~mL}$, respectively. The CEM consisted of a Nafion 117 membrane (DuPont Co., USA), and these experiments were carried out at room temperature. The anode feed consisted of pig slurry, the composition of which is indicated in Table 1, which was filtered through a $125-\mu \mathrm{m}$ sieve before use. The catholyte was $0.1 \mathrm{M}$ PBS. Anolyte and catholyte samples were taken at the beginning and the end of each cycle. The voltage applied was fixed at $1 \mathrm{~V}$ and three different batch periods were carried out to check the 
effect of time: three batchs of 1 day, two batchs of 2 days and two batchs of 3 days. The power supply was controlled, the voltage was measured, and the anode were inoculated in the same way as MEC-1X.

\section{Analytical methods}

Total organic carbon (TOC) and total nitrogen (TN) were measured in duplicate by a TOC analyser (multi N/C 3100; Analytikjena, Germany). Ammonium was measured according to the standard method ${ }^{[16]}$ using an ion-selective electrode (NH3 781 pH/Ion Meter; Metrohm, Switzerland). The $\mathrm{pH}$ was measured using a pH meter (GLP 21; Crison Instruments, Spain). Volatile fatty acids (VFAs) were determined using a gas chromatograph (CP3800 GC; Varian, USA) equipped with a flame ionisation detector, with helium used as the career gas. The VFA samples were pretreated following a method described elsewhere ${ }^{[17]}$.

\section{Results and discussion}

\section{Preliminary result in MEC-1X}

The anodes were inoculated with sewage sludge and $1 \mathrm{~V}$ was applied between the anode and 
cathode, following the procedure described above. After 20 days, once the current had stabilised, the cells were operated in batch mode using digestate as the anolyte at different applied voltages $(0.6,1.0$ and $1.4 \mathrm{~V})$ in order to evaluate to what extent migration phenomena influence nitrogen recovery. Two different catholytes were used, $\mathrm{PBS}$ and $\mathrm{NaCl}$, both at a concentration of $0.1 \mathrm{M}$. Current densities (Fig. 1) were very much independent of both the applied potential and the catholyte being used, which may indicate that substrate degradation was the limiting step (i.e., organic carbon was likely not bioavailable for bioelectricity production) ${ }^{[18]}$. Figure 2 suggest that this might be the case, as the removal of total organic carbon (TOC) does not seem to depend on the applied voltage either. Moreover, the current densities were below $5 \mathrm{~A} \cdot \mathrm{m}^{-2}$, the threshold value established by Liu et al. ${ }^{[19]}$ for which diffusion predominates over migration in ammonia recovery. This means that nitrogen recovery on the catholyte occurred independent of the applied potential for the particular substrate used in this study (digestate). In contrast, the catholyte seems to have some impact on nitrogen recovery, with lower recovery rates obtained when the $\mathrm{NaCl}$ solution was used. Ammonia loss through volatilisation might explain the lower recovery rate with $\mathrm{NaCl}$, as the ammonia fraction begins to be significant at $\mathrm{pH}$ above $8\left(30^{\circ} \mathrm{C}\right)$ ${ }^{[20]}$; however, in this study the catholyte $\mathrm{pH}$ reached 9 when using $\mathrm{NaCl}$ and did not rise above 7.5 when using PBS (Fig. 3). Moreover, a pH between 9.0 and 9.4 is the optimum range for the rapid precipitation of struvite from the solution ${ }^{[21]}$, which can cause energy loss due to the formation of precipitate on the cathode surface ${ }^{[22]}$. In contrast, when using PBS as the catholyte, 
the $\mathrm{pH}$ was fairly constant (below 7.5), as mentioned above, which means that the risk of ammonia volatilisation and struvite precipitation are minimized. Previous studies have also found that a PBS-based catholytes offer better results in terms of energy recovery (as hydrogen) in a MEC [23]. The results presented in Figure 2 also show that regardless of the catholyte being used, over $70 \%$ of the maximum ammonia recovery and maximum TOC removal were achieved within the first 8 hours in all the experiments. From this moment on, the slopes of the NT and TOC profiles began to decline, probably due to the effect of charge exchange attempting to maintain overall charge neutrality ${ }^{[12]}$ and the consumption of biodegradable organic matter, respectively.

These same tests were replicated using pig slurry as anolyte, obtaining similar results to those obtained with digestate: applied voltage did not seem to have any visible effect on nitrogen recovery efficiencies and PBS offered better results than $\mathrm{NaCl}$. However, applied voltage seemed to have a more positive effect on TOC removal efficiencies when using pig slurry (Fig. 4). This might probably be attributed to the presence of more easily degradable organic matter in the used pig slurry than in the digestate.

\section{$M E C-5 X$ and MEC-10x tests}

Following the preliminary results on the MEC-1X scale, the same double chamber configuration 
was tested at two different scales ( $5 \mathrm{X}$ and $10 \mathrm{X}$ ), although this time pig slurry, which has a higher nitrogen content than the digestate, was used as the anolyte. The PBS solution was used as the catholyte to avoid $\mathrm{pH}$ rises that might result in nitrogen loss and salt precipitation on the cathode. Again, the anodes of the MECs were inoculated with anaerobic digestate from the local WW treatment plant and effluent from the bioanode of a previous MEC which had been supplemented with sodium acetate. After inoculation, the reactors were fed with a synthetic medium over nine cycles until the current stabilised, then the feed was changed to pig slurry, requiring 20 days for the current to stabilise again. Applied voltage was set at $1 \mathrm{~V}$ to optimize TOC removal (compared to $0.6 \mathrm{~V}$ ) without incurring in an excessive energy consumption that might probably result from using 1.4V (Figure 4c). Interestingly, although MEC-5X developed a slightly higher peak current density, the current profiles for both reactors followed similar trends (Fig. 5). This suggests that doubling the reactor volume does not have a significant impact on the reactor performance, at least when using a substrate with low biodegradability such as pig slurry. The maximum current densities are similar to the results found in other lab-scale MECs fed with pig slurry ${ }^{[25]}$. Nitrogen recovery and organic matter removal were evaluated in batch tests with a duration of 12 hours, 1, 2 or 3 days. For both nitrogen (Fig. 6) and TOC (Fig. 7), it was observed that the majority was removed during the first 12 hours day, and that increasing the batch duration to 1 , 2 or 3 days did not bring any additional improvement. This is in accordance with the result 
obtained using digestate in MEC-1X (Fig. 2), where the rate of nitrogen removal and current production (which can be linked to TOC degradation) were the highest during the first 8 hours of the tests, after which point they reached a plateau. Most of the nitrogen removed in the anode was recovered on the cathode as $\mathrm{NH}_{4}{ }^{+}$, achieving recovery rates of up to $50 \%$, which are similar to than that obtained with pig slurry in MEC-1X but they are lower than that obtained with the digestate in MEC-1X. This is probably due to the higher nitrogen concentration in the pig slurry, and is consistent with other studies that reported the highest nitrogen removal efficiencies with the lowest ammonia transport ${ }^{[26]}$. Regarding the ammonia recovery rate, the highest values were 10.9 and $8.3 \mathrm{gN} \cdot \mathrm{m}^{-2} \cdot \mathrm{day}^{-1}$ for MEC-5X and MEC-10X, respectively. These results correspond with efficiencies of 53, 47 and 42\% for MEC-1X, MEC-5X and MEC-10X, respectively. Therefore, a decrease in the ammonium recovery efficiencies is observed when the reactor volume is increased.

The concentration of TOC in the pig slurry averaged $2.8 \mathrm{~g} \cdot \mathrm{L}^{-1}$ (Fig. 5), and only 300 mgTOC $\cdot$ Lanode $^{-1} \cdot$ day $^{-1}$ was removed, most of which occurred on the first day and was correlated with current decrease, which represents a removal rate of about $9.3 \%$. Regarding VFAs, only acetate was identified, which showed an average concentration of $173 \mathrm{mg} \cdot \mathrm{L}^{-1}$ at the beginning of the test and was completely removed by the end of the test.

\section{Conclusion}


In this study, the effect of applied voltage, catholyte and reactor size on nitrogen recovery using MEC technology was assessed. The applied voltage did not seem to have a noticeable effect on ammonia recovery, maybe due to the fact that diffusion predominates over migration as a low-current density is produced by the low biodegradability of the substrates used. Moreover, the use of PBS as the catholyte allowed the $\mathrm{pH}$ to be controlled, also avoiding the appearance of precipitates and loss of ammonium due to volatilisation. Doubling the reactor size (from 500 to $1000 \mathrm{~mL}$ ) did not appear to have a clear impact on current density, although the ammonia recovery rate efficiency decreased from 47 to $42 \%$ when the reactor volume was doubled.

\section{Acknowledgments}

This research was supported by the European Union Horizon 2020 research and innovation programme (grant no. 668128-Newfert-H2020-BBI-PPP-2014-1). M.I. San-Martín and R. Mateos are supported by a FPU fellowship grant (FPU13/04014 and FPU14/01573, respectively) from the Spanish Ministry of Economy and Competitiveness.

\section{References}

[1] Jensen, L.S. Animal manure fertiliser value, crop utilisation and soil quality impacts. Anim. manure Recycl. Treat. Manag. 2013, 295-328. 
[2] Santos, A.; Bustamante, M.A.; Tortosa, G.; Moral, R.; Bernal, M.P. Gaseous emissions and process development during composting of pig slurry: the influence of the proportion of cotton gin waste. J. Clean. Prod. 2016, 112, 81-90.

[3] Sommer, S.G.; Maahn, M.; Poulsen, H.D.; Hjorth, M.; Sehested, J. Interactions between phosphorus feeding strategies for pigs and dairy cows and separation efficiency of slurry. Environ. Technol. 2008, 29(1), 75-80.

[4] Sommer, S.G.; Christensen, M.L.; Schmidt, T.; Jensen, L.S. Animal manure recycling: treatment and management. John Wiley \& Sons: , 2013.

[5] Li, W.-W.; Yu, H.-Q.; Rittmann, B.E. Chemistry: Reuse water pollutants. Nature 2015, 528, $29-31$.

[6] Zhang, Y.; Angelidaki, I. Submersible microbial desalination cell for simultaneous ammonia recovery and electricity production from anaerobic reactors containing high levels of ammonia.

Bioresour. Technol. 2015, 177, 233-239.

[7] Atandi, E.; Rahman, S. Prospect of anaerobic co-digestion of dairy manure: a review.

Environ. Technol. Rev. 2012, l(1), 127-135.

[8] Lin, H.; Wu, X.; Nelson, C.; Miller, C.; Zhu, J. Electricity generation and nutrients removal from high-strength liquid manure by air-cathode microbial fuel cells. J. Environ. Sci. Heal. Part A 2016, 51(3), 240-250.

[9] Wang, H.; Ren, Z.J. A comprehensive review of microbial electrochemical systems as a 
platform technology. Biotechnol. Adv. 2013, 31(8), 1796-1807.

[10] Arredondo, M.R.; Kuntke, P.; Jeremiasse, A.W.; Sleutels, T.; Buisman, C.J.N.; Heijne, A. ter. Bioelectrochemical systems for nitrogen removal and recovery from wastewater. Environ. Sci.

Water Res. Technol. 2015, 1(1), 22-33.

[11] Zhang, Y.; Angelidaki, I. Counteracting ammonia inhibition during anaerobic digestion by recovery using submersible microbial desalination cell. Biotechnol. Bioeng. 112(7), 1478-1482.

[12] Kuntke, P.; Geleji, M.; Bruning, H.; Zeeman, G.; Hamelers, H.V.M.; Buisman, C.J.N.

Effects of ammonium concentration and charge exchange on ammonium recovery from high strength wastewater using a microbial fuel cell. Bioresour. Technol. 2011, 102(6), 4376-4382.

[13] Kuntke, P.; Śmiech, K.M.; Bruning, H.; Zeeman, G.; Saakes, M.; Sleutels, T.H.J.A.; Hamelers, H.V.M.; Buisman, C.J.N. Ammonium recovery and energy production from urine by a microbial fuel cell. Water Res. 2012, 46(8), 2627-2636.

[14] Wu, X.; Modin, O. Ammonium recovery from reject water combined with hydrogen production in a bioelectrochemical reactor. Bioresour. Technol. 2013, 146, 530-536.

[15] Mateos, R.; Alonso, R.M.; Escapa, A.; Morán, A. Methodology for Fast and Facile Characterisation of Carbon-Based Electrodes Focused on Bioelectrochemical Systems Development and Scale Up. Materials (Basel). 2017, 10(1).

[16] Federation, W.E.; Association, A.P.H. Standard methods for the examination of water and wastewater. Am. Public Heal. Assoc. Washington, DC, USA 2005. 
[17] Martínez, E.J.; Gil, M. V; Rosas, J.G.; Moreno, R.; Mateos, R.; Morán, A.; Gómez, X. Application of thermal analysis for evaluating the digestion of microwave pre-treated sewage sludge. J. Therm. Anal. Calorim. 2017, 127(2), 1209-1219.

[18] Gil-Carrera, L.; Escapa, A.; Carracedo, B.; Morán, A.; Gómez, X. Performance of a semi-pilot tubular microbial electrolysis cell (MEC) under several hydraulic retention times and applied voltages. Bioresour. Technol. 2013, 146, 63-69.

[19] Liu, Y.; Qin, M.; Luo, S.; He, Z.; Qiao, R. Understanding ammonium transport in bioelectrochemical systems towards its recovery. Sci. Rep. 2016, 6 .

[20] Bonmati, A.; Flotats, X. Pig slurry concentration by vacuum evaporation: influence of previous mesophilic anaerobic digestion process. J. Air Waste Manage. Assoc. 2003, 53(1), $21-31$.

[21] Booker, N.A.; Priestley, A.J.; Fraser, I.H. Struvite Formation in Wastewater Treatment Plants: Opportunities for Nutrient Recovery. Environ. Technol. 1999, 20(7), 777-782.

[22] Almatouq, A.; Babatunde, A.O. Concurrent phosphorus recovery and energy generation in mediator-less dual chamber microbial fuel cells: mechanisms and influencing factors. Int. J. Environ. Res. Public Health 2016, 13(4), 375.

[23] Yossan, S.; Xiao, L.; Prasertsan, P.; He, Z. Hydrogen production in microbial electrolysis cells: Choice of catholyte. Int. J. Hydrogen Energy 2013, 38(23), 9619-9624.

[24] Hassan, M.; Fernandez, A.S.; San Martin, I.; Xie, B.; Moran, A. Hydrogen evolution in 
microbial electrolysis cells treating landfill leachate: Dynamics of anodic biofilm. Int. J.

Hydrogen Energy 2018, 43(29), 13051-13063.

[25] Cerrillo, M.; Oliveras, J.; Viñas, M.; Bonmatí, A. Comparative assessment of raw and digested pig slurry treatment in bioelectrochemical systems. Bioelectrochemistry 2016, 110, 69-78.

[26] Rodríguez Arredondo, M.; Kuntke, P.; Heijne, A. ter; Hamelers, H.V.M.; Buisman, C.J.N. Load ratio determines the ammonia recovery and energy input of an electrochemical system. Water Res. 2017, 111, 330-337.

\section{FIGURE CAPTIONS}

Figure 1. MEC-1X reactor current densities with different voltages applied $(0.6,1$ and $1.4 \mathrm{~V})$ and different catholytes (PBS and $\mathrm{NaCl}$ ) when digestate is used as anolyte.

Figure 2. Total organic carbon removal efficiency in the anodic chamber and nitrogen recovery efficiency in the cathodic chamber when phosphate-buffered saline (A and C) and $\mathrm{NaCl}$ (B and D) were used as the catholyte and digestate as anolyte in MEC-1X.

Figure 3. Current density at $1 \mathrm{~V}$ when phosphate-buffered solution (A) and $\mathrm{NaCl}(\mathrm{B})$ were used as the catholyte and digestate as anolyte in MEC-1X.

Figure 4. Total organic carbon removal efficiency in the anodic chamber and nitrogen recovery efficiency in the cathodic chamber when phosphate-buffered saline ( $\mathrm{A}$ and $\mathrm{C}$ ) and $\mathrm{NaCl}(\mathrm{B}$ and D) were used as the catholyte and pig slurry as anolyte in MEC-1X. 
Figure 5. Current density in MEC-5X and MEC-10X under different batch times.

Figure 6. Variation in nitrogen concentration $\left(\mathrm{g} \cdot \mathrm{L}^{-1}\right)$ in the anolyte at the beginning and the end of the batch period (12 hours, 1, 2 or 3 days) in MEC-5X and in MEC-10X.

Figure 7. Variation in total organic carbon (TOC) concentration $\left(\mathrm{g} \cdot \mathrm{L}^{-1}\right)$ in the anolyte at the beginning and the end of the batch period (12 hours, 1, 2 or 3 days) in MEC-5X and in MEC-10X. 


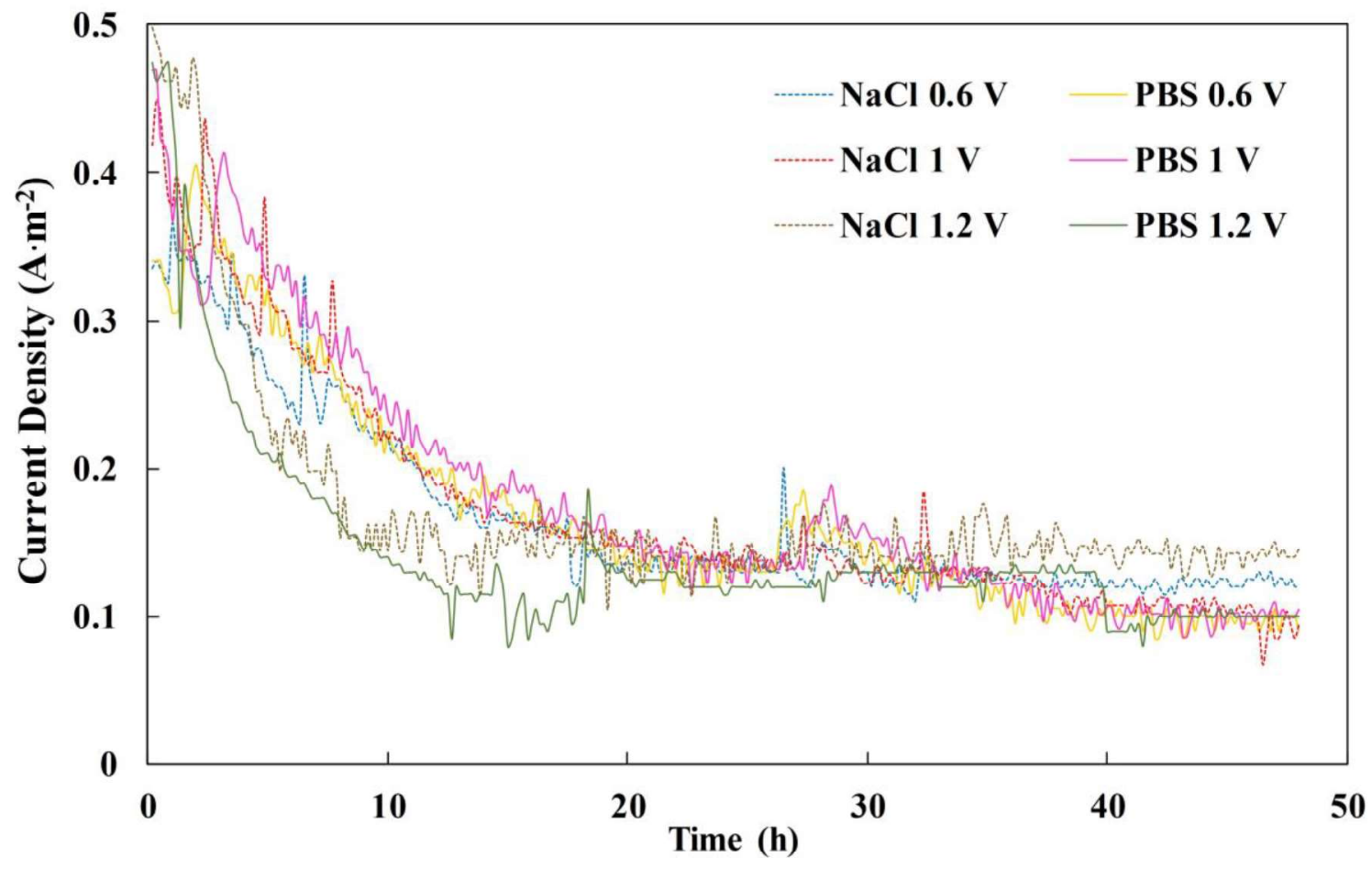

Fig. 1 

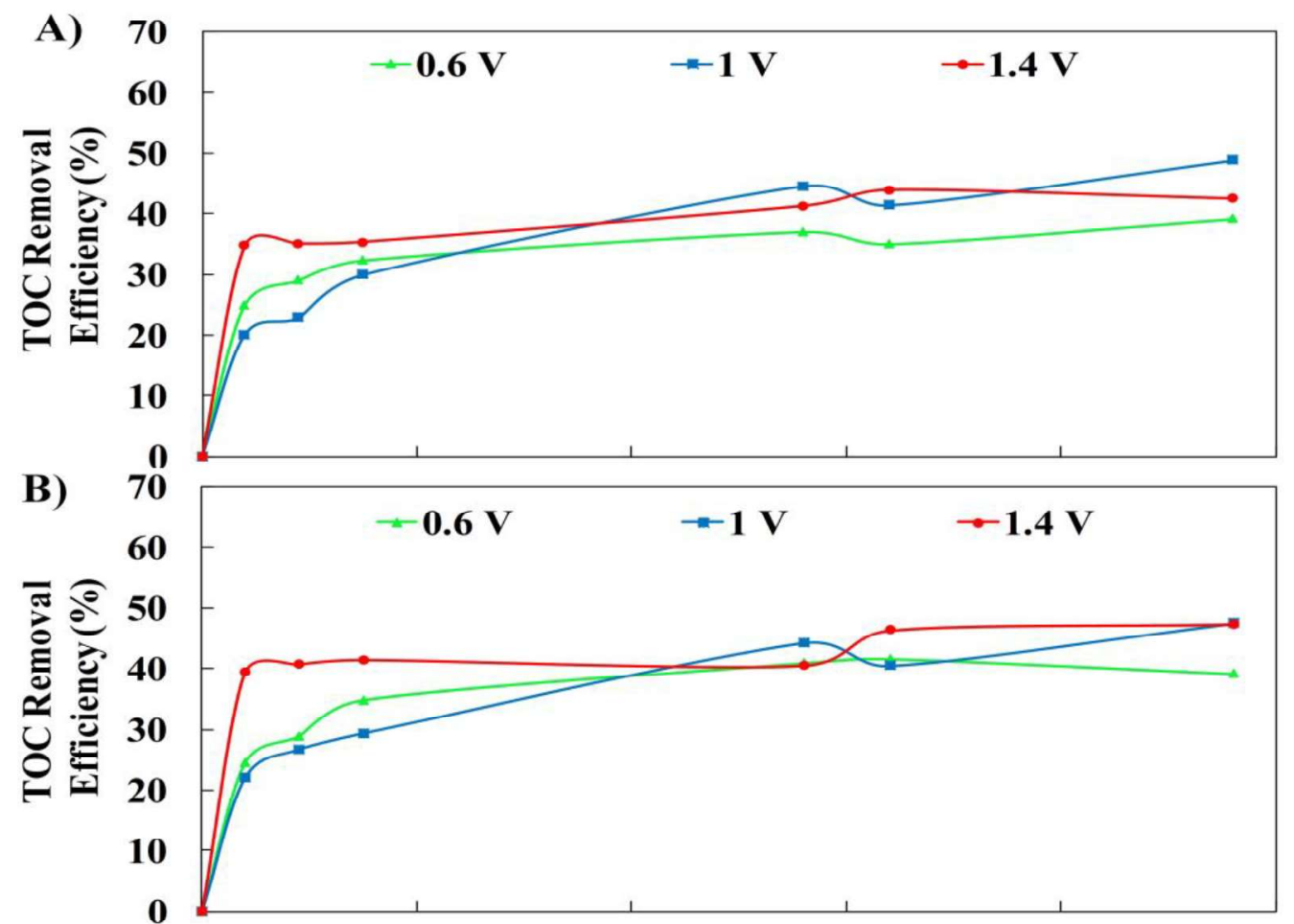

C) 70

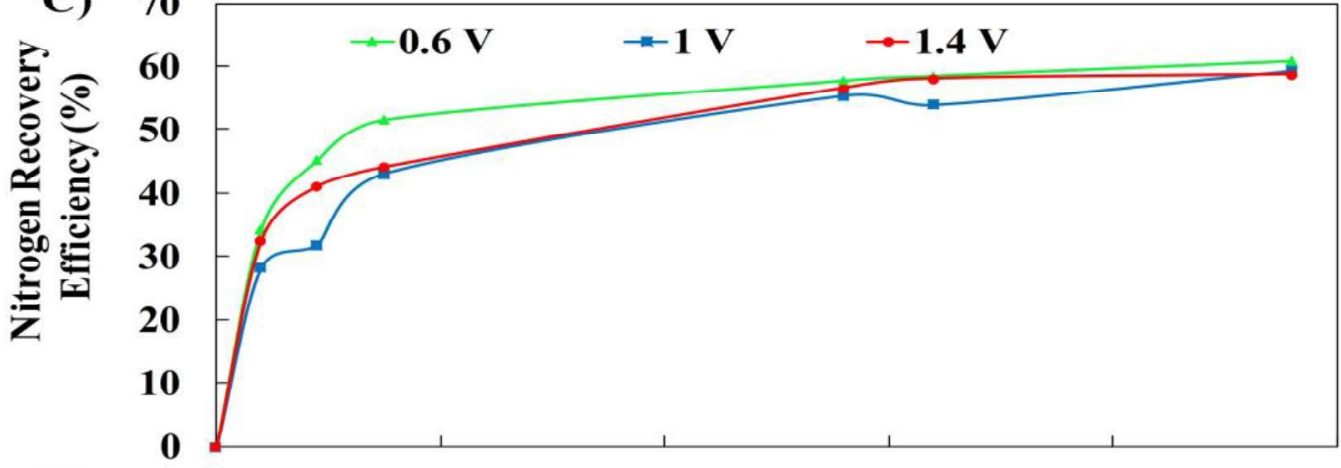

D) 70

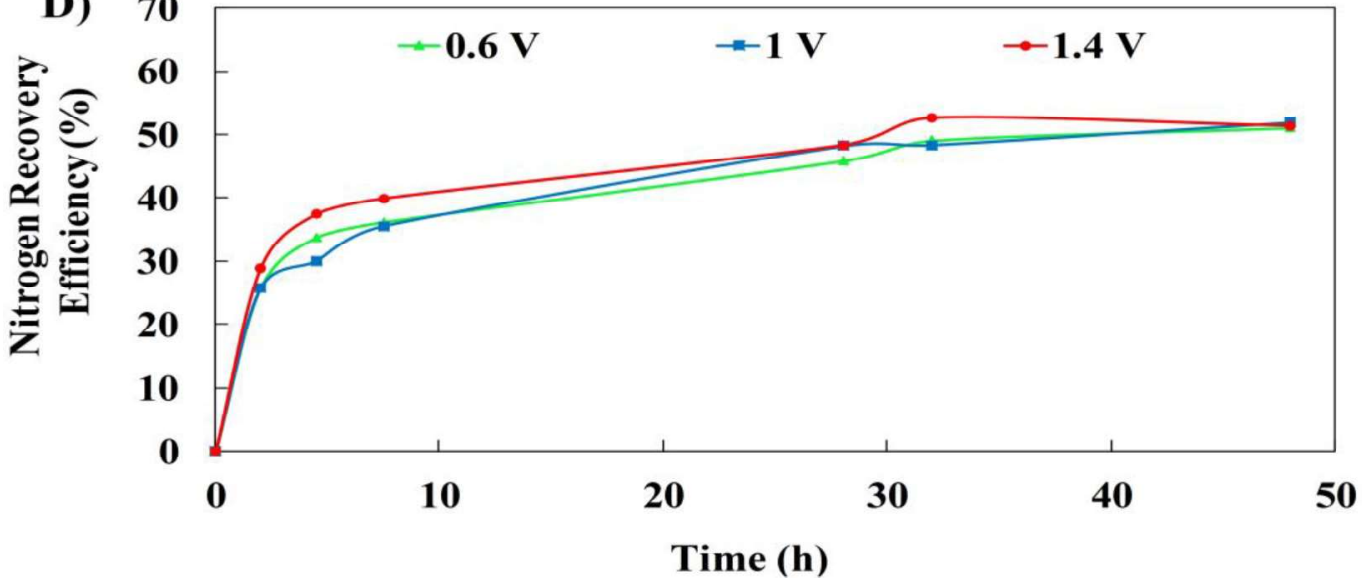

Fig. 2 

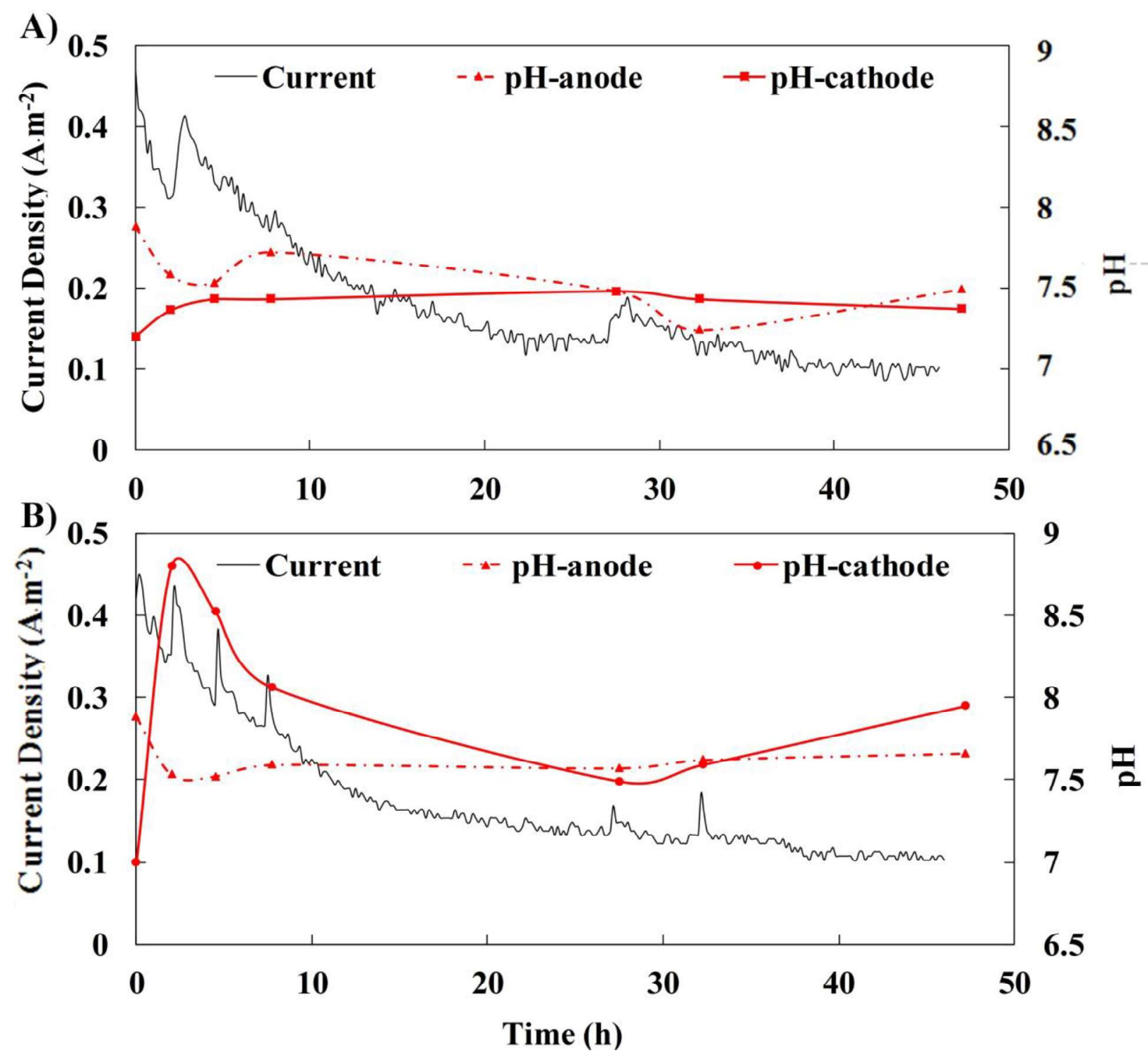

Fig. 3 

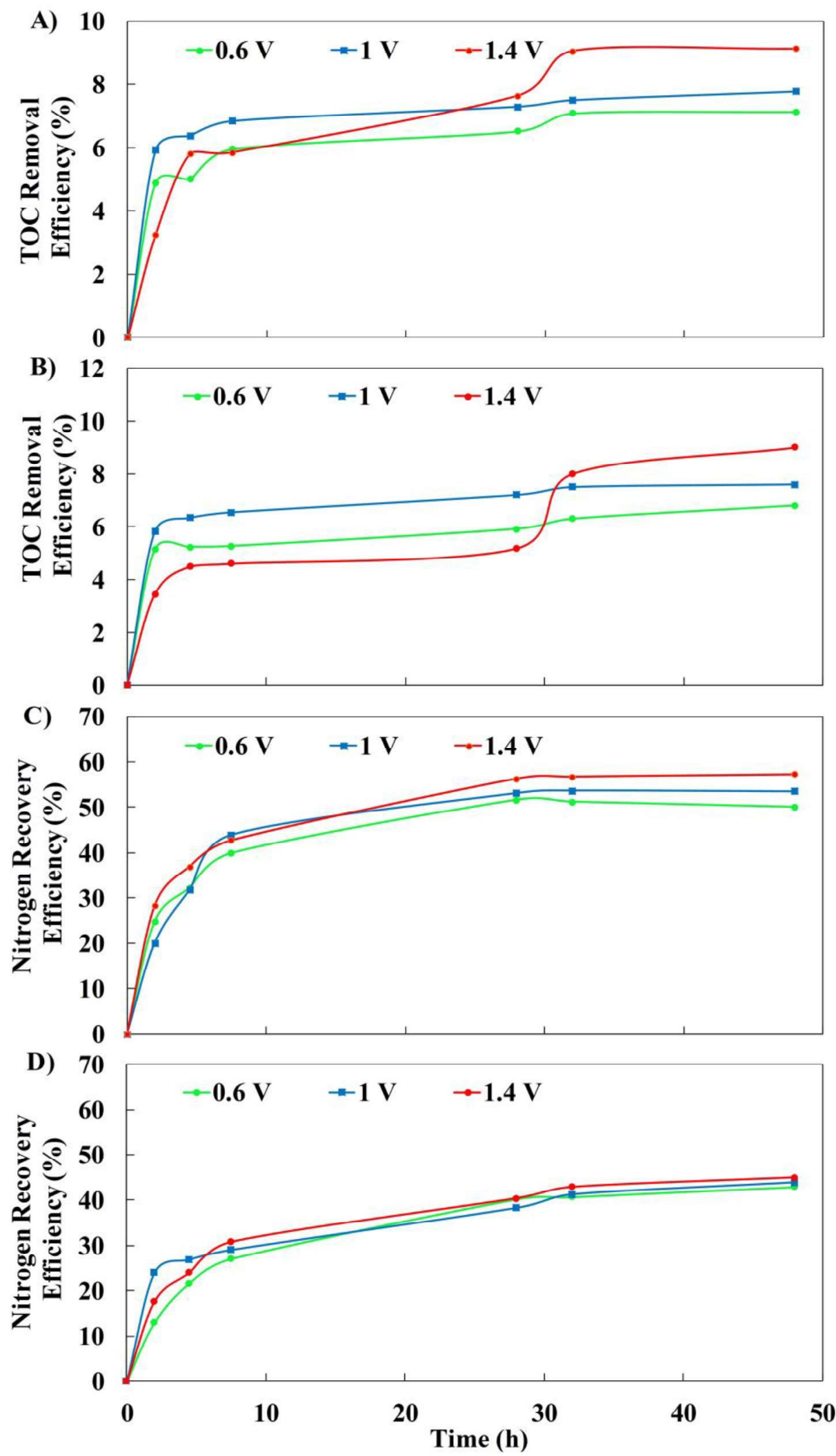

Fig. 4 


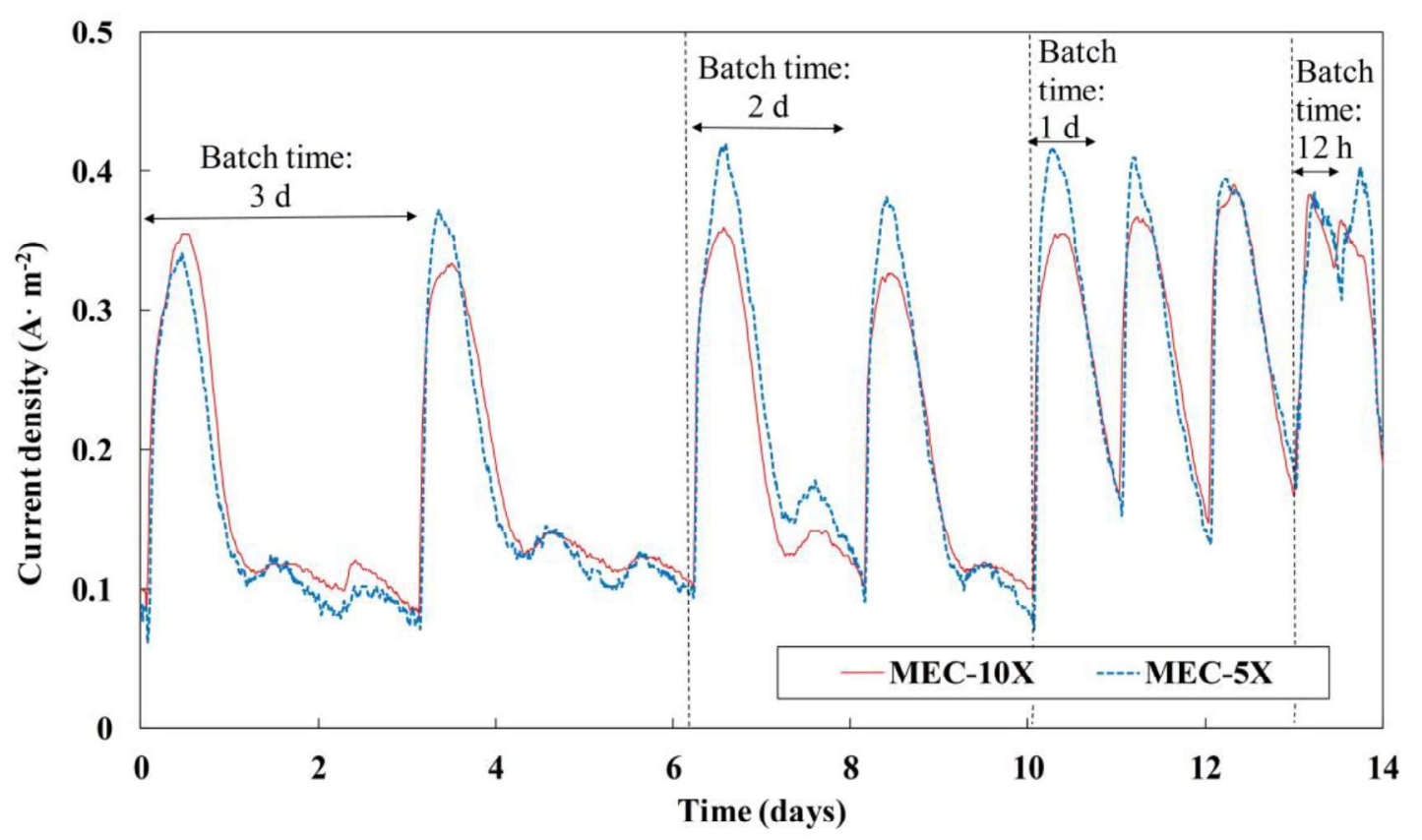

Fig. 5 


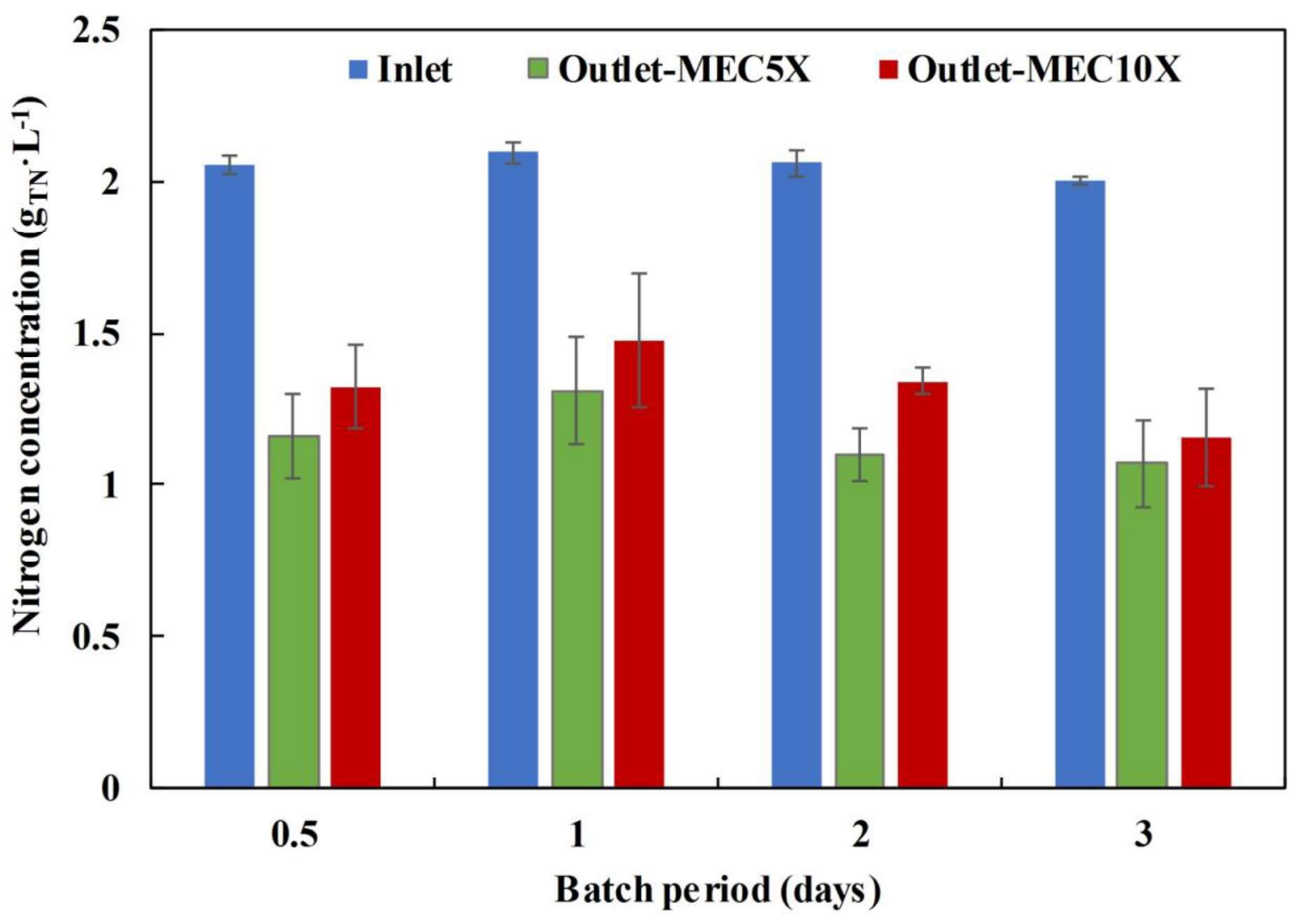

Fig. 6 


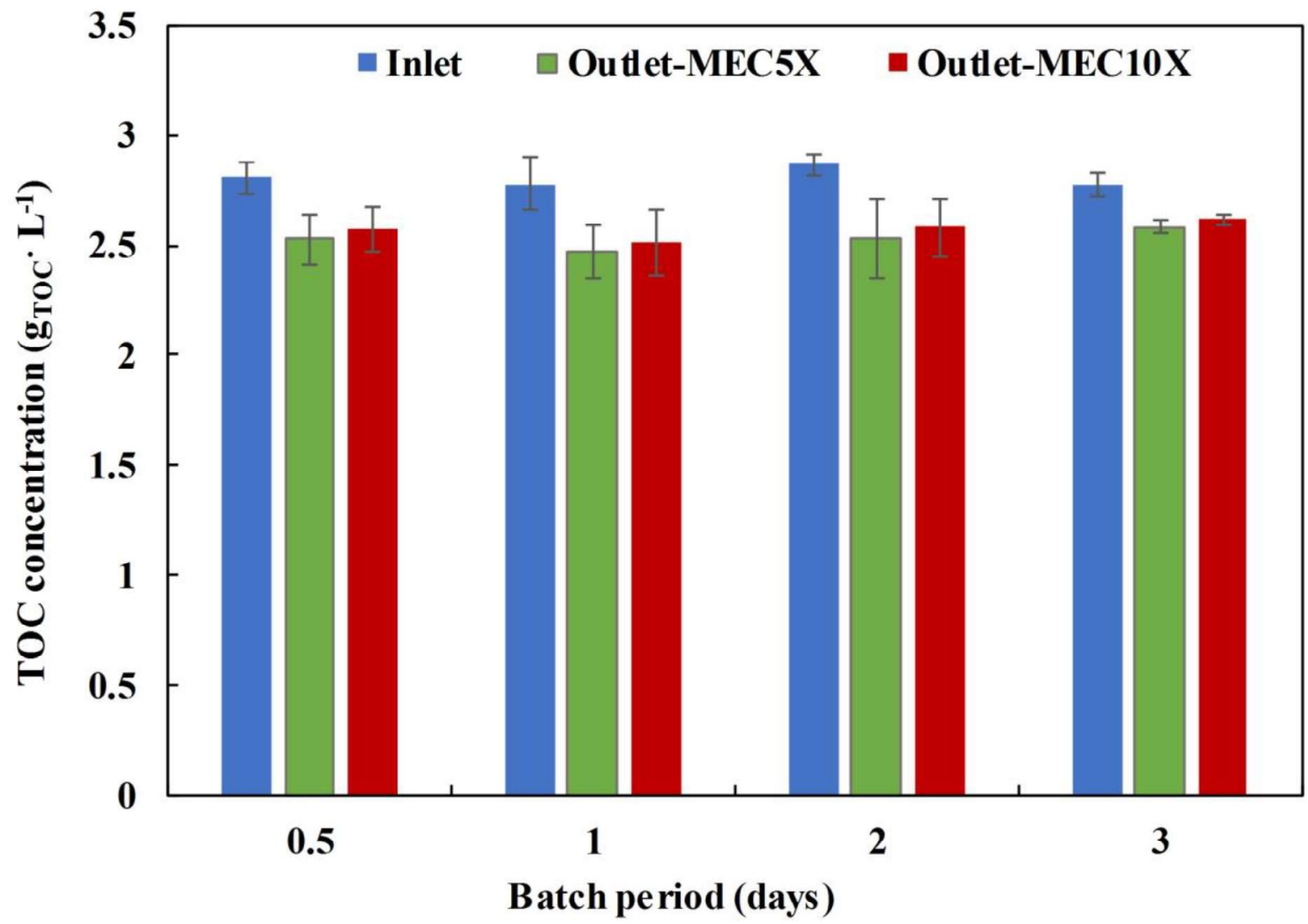

Fig. 7 
Table 1. Digestate and pig slurry composition. Average concentration of Total Organic Carbon

(TOC), Acetate, Total Nitrogen (TN), Total Ammonia Nitrogen (TAN), Phosphate, Sulphate,

Chloride, Total Solids (TS), Volatile Solids (VS) and pH and Conductivity.

\begin{tabular}{ccc}
\hline & Digestate & Pig slurry \\
\hline TOC $(\mathrm{g} / \mathrm{L})$ & 0.99 & 2.81 \\
Acetate $(\mathrm{mg} / \mathrm{L})$ & 2 & 173 \\
TN $(\mathrm{g} / \mathrm{L})$ & 1.61 & 2.03 \\
TAN $(\mathrm{g} / \mathrm{L})$ & 1.55 & 1.9 \\
Phosphate $(\mathrm{mg} / \mathrm{L})$ & 726 & 32 \\
Sulphate $(\mathrm{mg} / \mathrm{L})$ & 253 & 34 \\
Chloride $(\mathrm{mg} / \mathrm{L})$ & 38 & 2060 \\
TS $(\mathrm{g} / \mathrm{kg})$ & 24 & 17.3 \\
VS $(\mathrm{g} / \mathrm{kg})$ & 11.2 & 7.6 \\
$\mathrm{pH}$ & 7.35 & 8.21 \\
Conductivity $(\mathrm{mS} / \mathrm{cm})$ & 24.1 & 26 \\
\hline
\end{tabular}




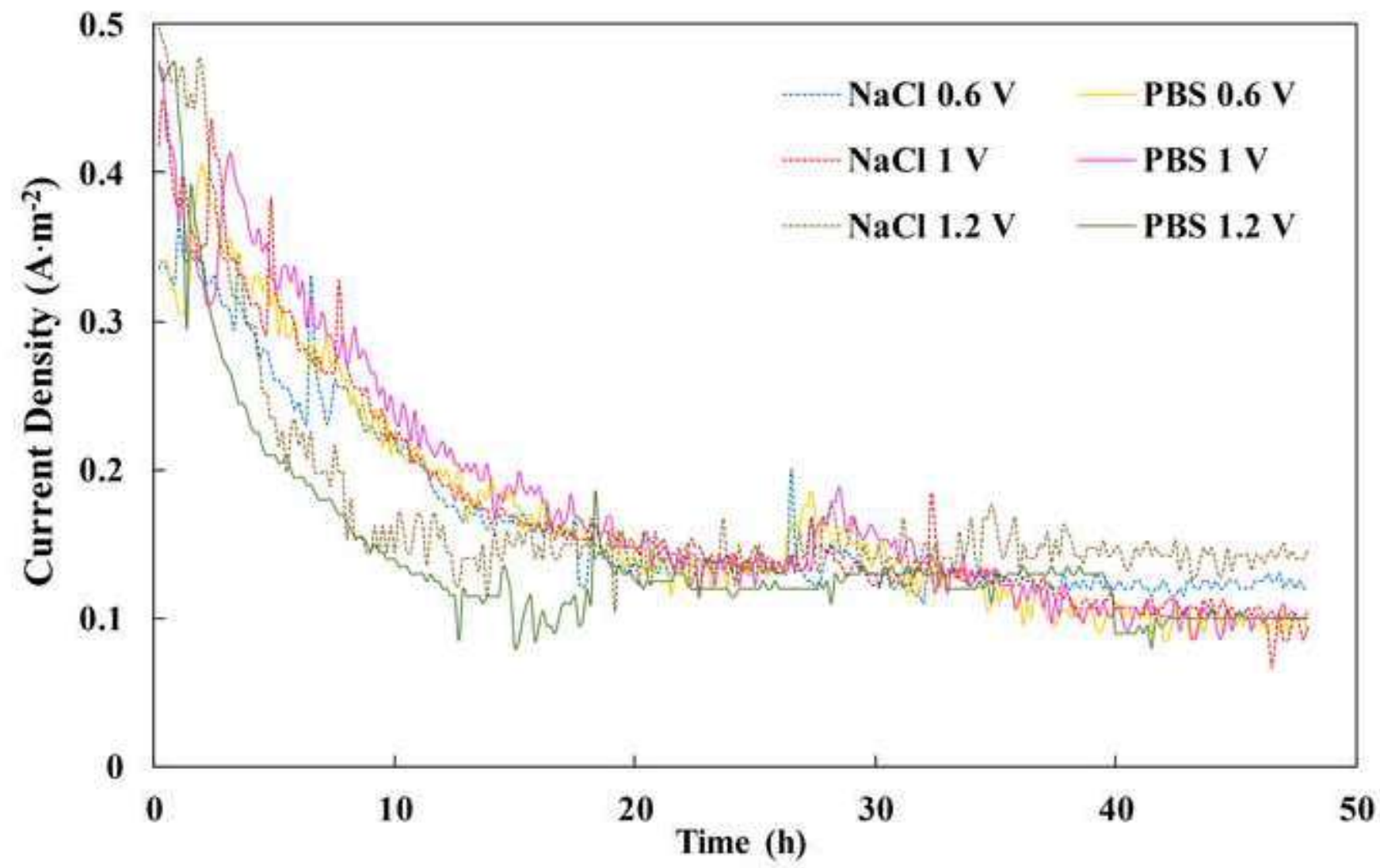



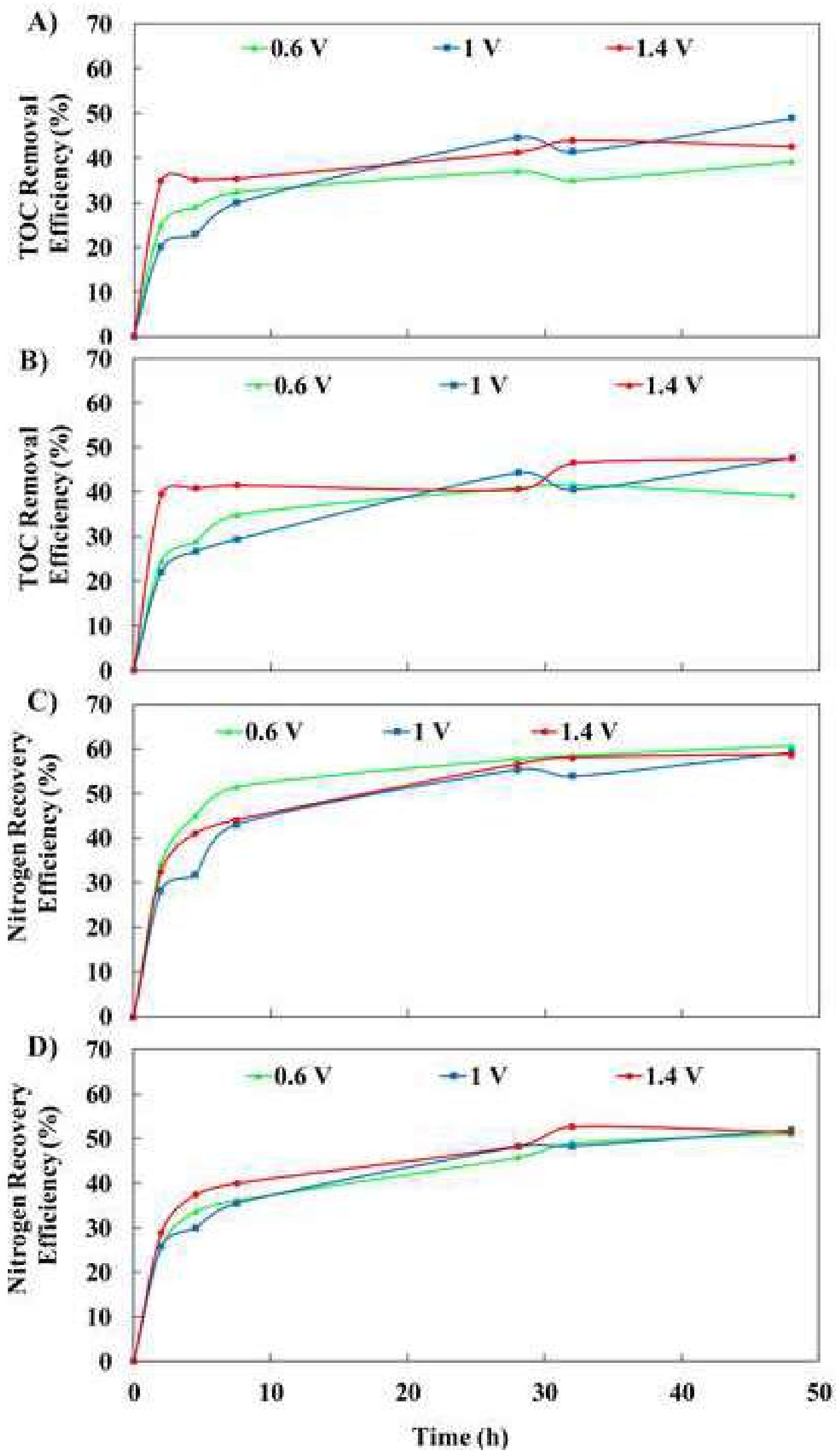

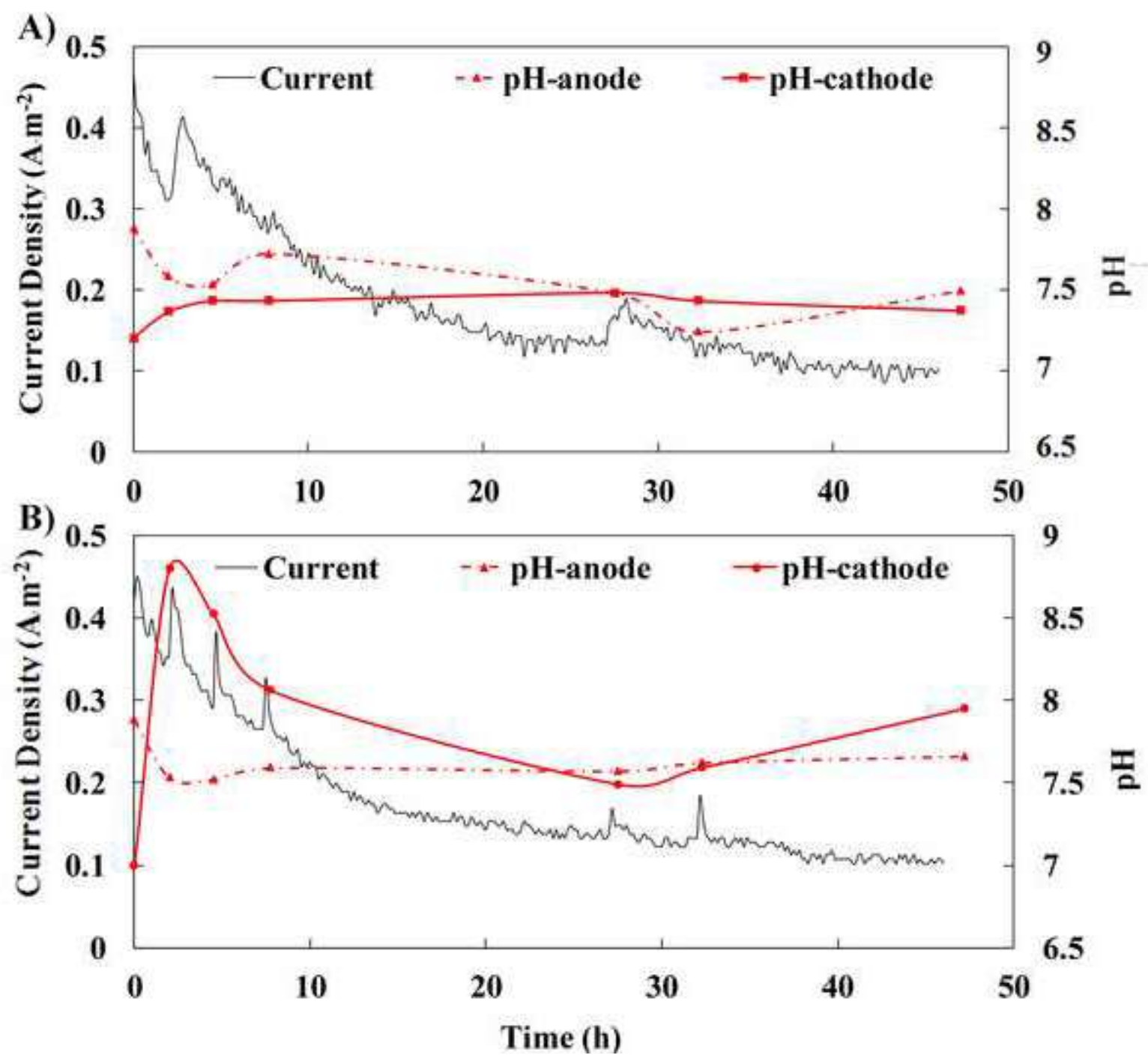

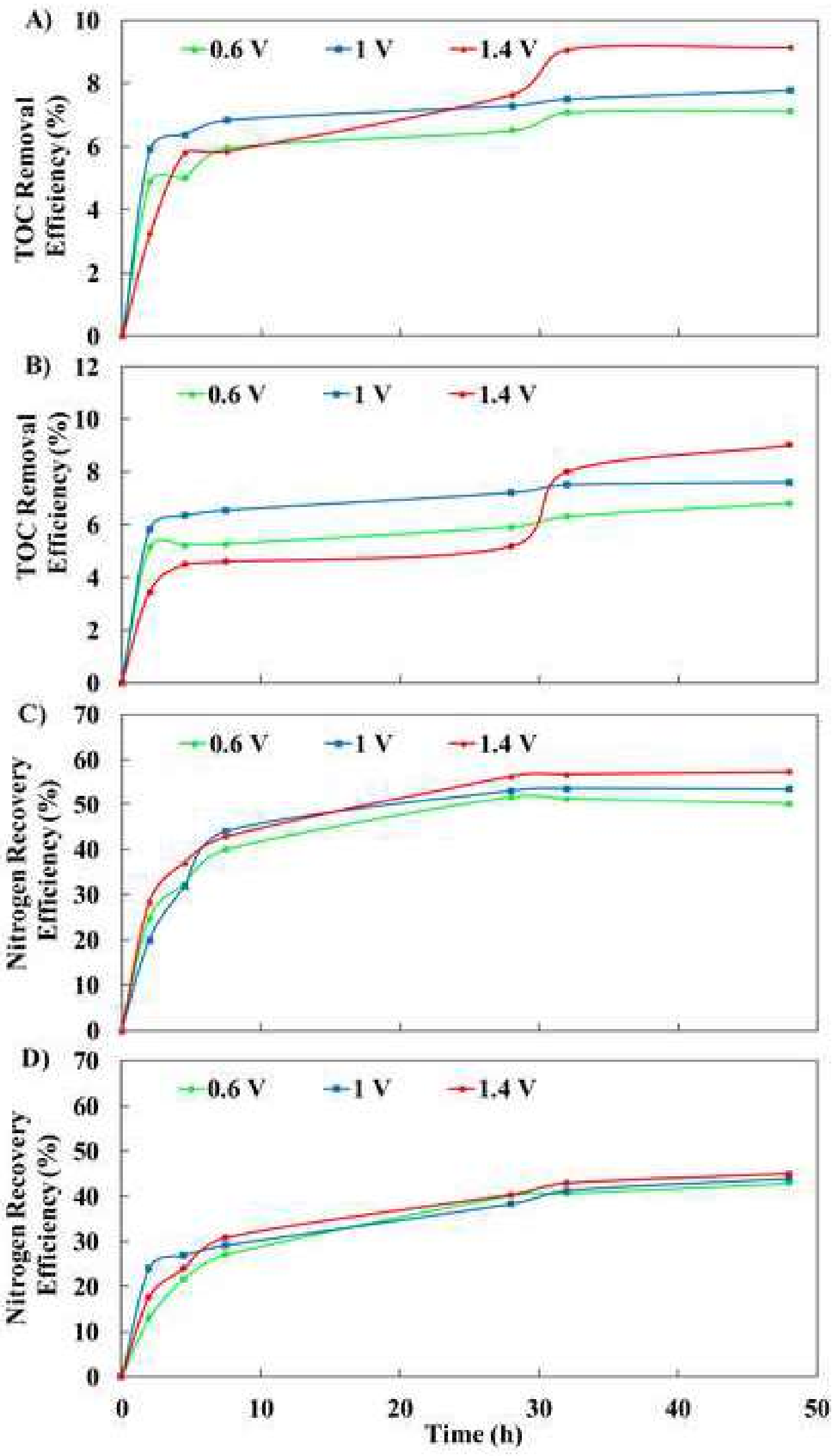


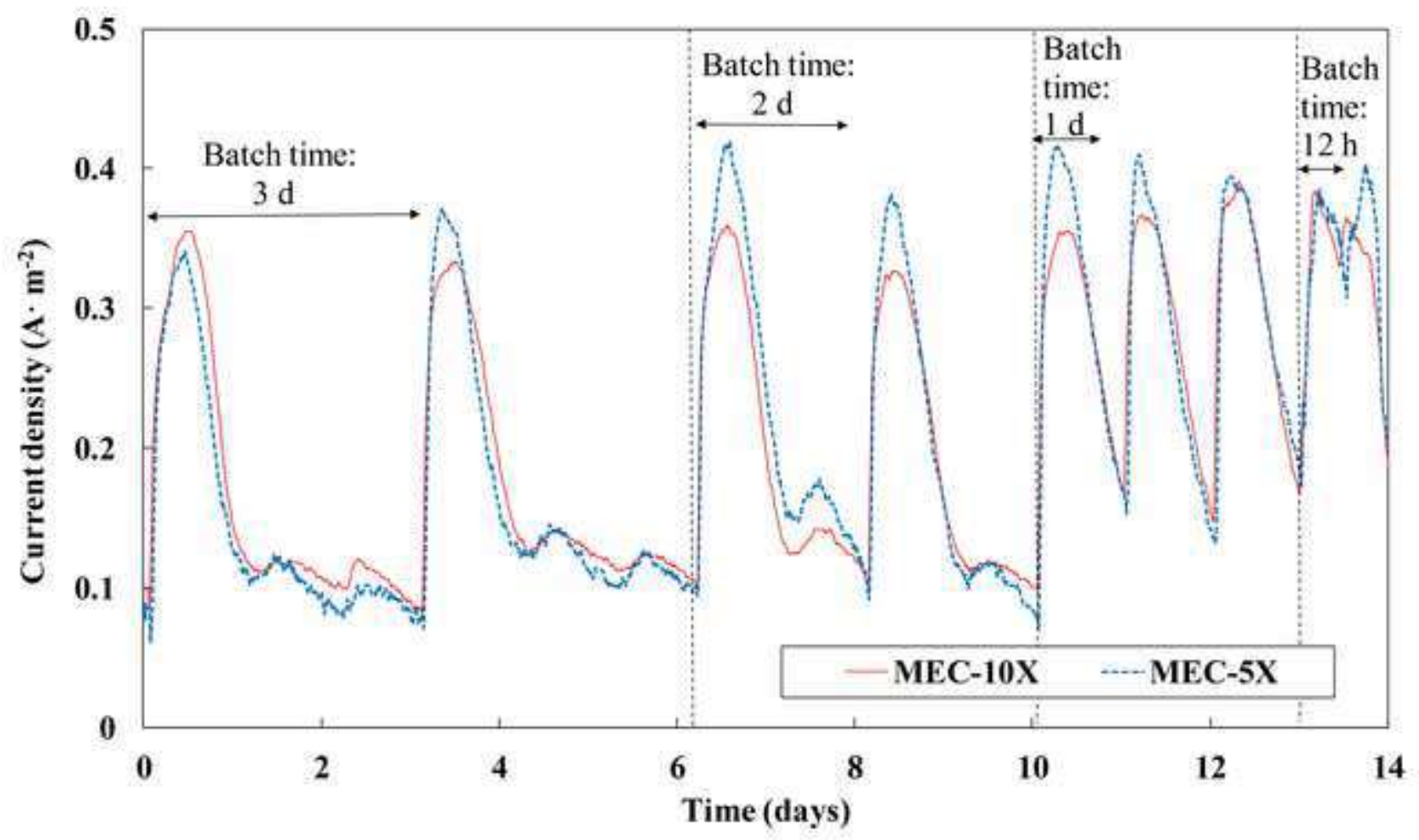




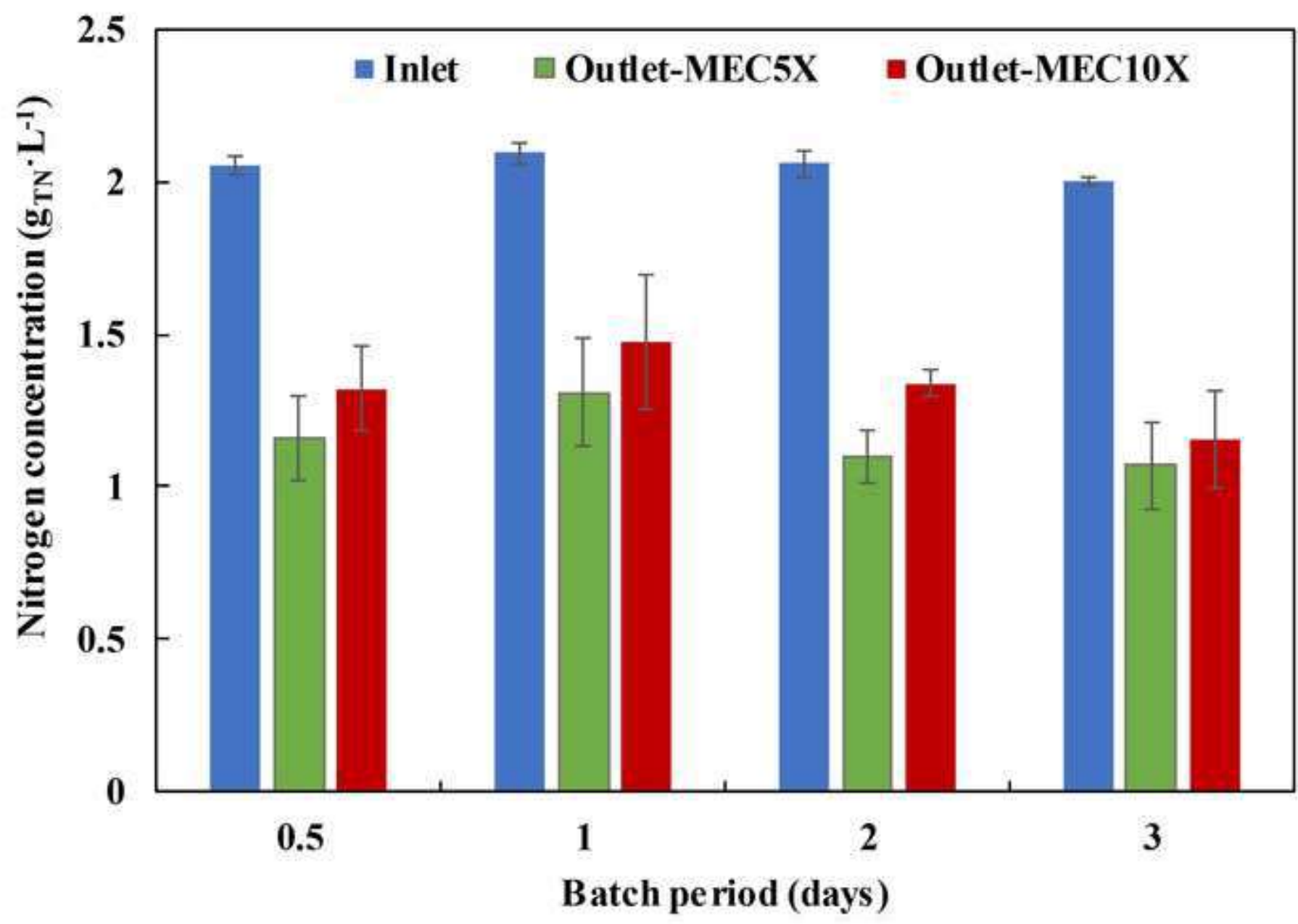




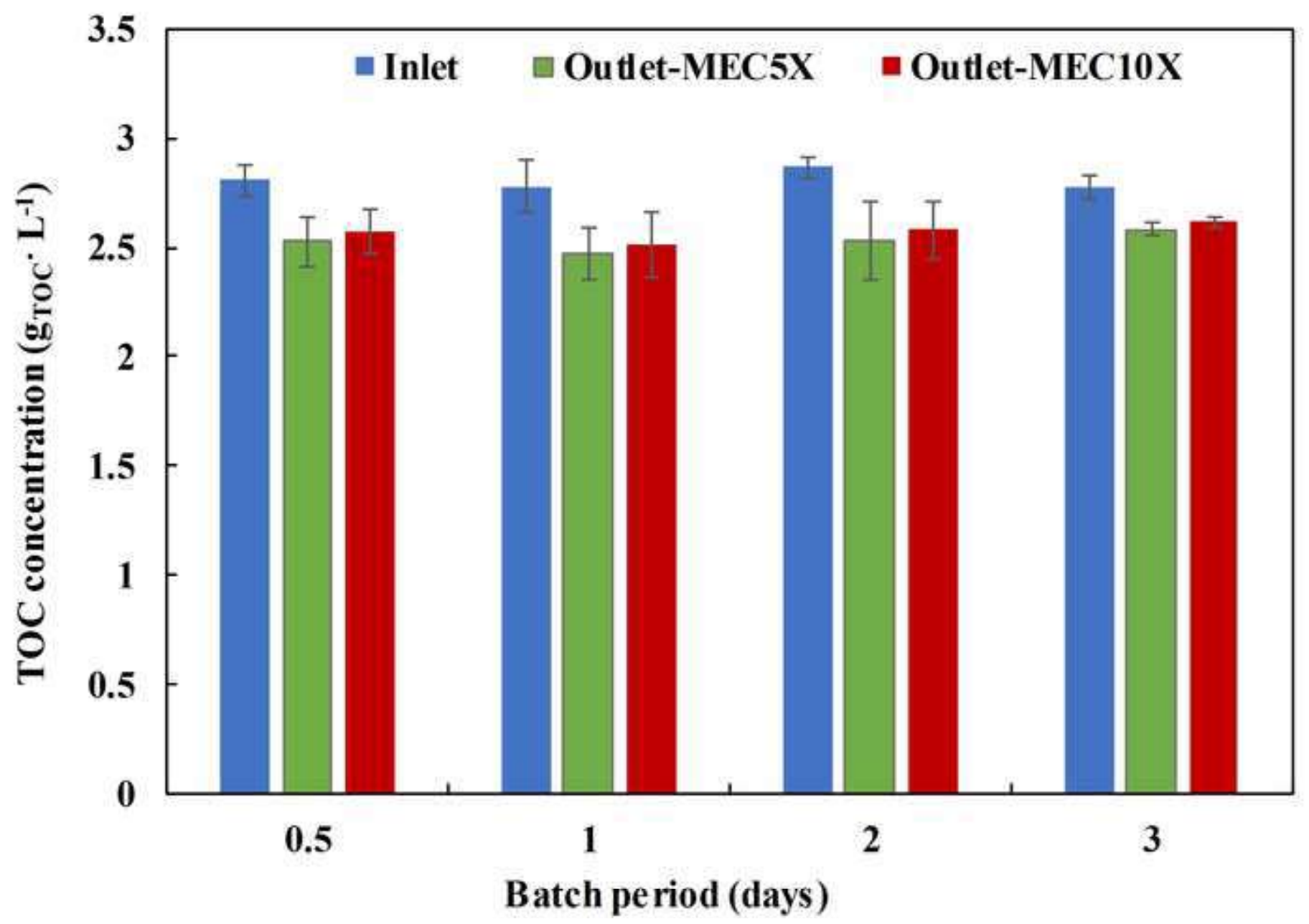

